\title{
CASAMENTO NA TOWNSHIP: UM ESTUDO SOBRE AS TRANSFORMAÇÕES ESTÉTICAS DO RITUAL
}

\author{
Aina Azevedo ${ }^{1}$
}

As particularidades que engendram qualquer análise ou um mero olhar sobre as cidades sul-africanas, colocam em suspeição homologias e comparações. Afinal, nada se iguala à segregação espacial racializada promovida ao longo do século XX naquele país, cujo apogeu se dá com a implementação do apartheid durante toda a metade do mesmo século. Elementos como esse motivam os autores Achille Mbembe e Sarah Nuttall a confrontar repetidas percepções sobre Johanesburgo - a metrópole africana - que insistem na análise do nascimento, da queda e da reconstrução da cidade segregada. Tais análises "subestimariam o grau em que a cidade sempre opera como lugar da fantasia, do desejo e da imaginação" (Mbembe \& Nuttall, 2008: 10).

Em consequência, muita atenção é dada à "geografia da pobreza, as remoções forçadas e aos distritos racialmente distinguidos", enquanto pouco se fala sobre as "categorias da afluência". Tais perspectivas, dedicadas ao entendimento da relação entre industrialização e urbanização, veem a cidade não como um "projeto estético", mas como um espaço de divisão. E um desses espaços é a township ${ }^{2}$ (Mbembe \& Nuttall, 2008: 11).

Enfatizada na literatura como "lugar da marginalidade, das lutas sociais e da contestação sobre benefícios públicos", a township não é percebida em termos de suas imbricações com a cidade, a centro, a homeland e o trânsito entre esses lugares. A literatura também falharia em situar a township em relação a outros tipos de aglomerações em outros lugares, como os guetos e as favelas (Mbembe \& Nuttall, 2008: 10-13).

Neste artigo, não tomo como minha a tarefa de produzir respostas à agenda de pesquisa supracitada, mas sigo na esteira das questões postas que indicam a necessidade de criar espaço para articular a "originalidade da modernidade Africana e des-familiarizar as leituras comuns da África" (Mbembe \& Nuttall, 2008: 9). Para tanto, me detenho na

\footnotetext{
${ }^{1}$ Universidade de Brasília, Brasil.

${ }^{2}$ Criadas durante o apartheid para a residência da população classificada como não branca - negros, indianos e coloureds - as townships geralmente são cidades afastadas dos centros urbanos, quer seja das capitais ou das cidades do interior, como cidades-satélites. Muitos desses locais padeciam e padecem ainda da falta de parte dos serviços públicos básicos, como saneamento, eletricidade e água.
}

Iluminuras, Porto Alegre, v. 16, n. 37, p.338-354, jan/jun. 2015 
performance de um ritual de casamento entre falantes de isiZulu, realizado em 2011, especialmente na township de Thokosa ${ }^{3}$, mas não só nela, para apontar os elementos estéticos que compõe a festa e tornam visível os pertencimentos das pessoas e as suas conexões espaciais.

Esses elementos vão desde objetos a animais, passando por roupas, cabelos, sons, casas redondas, objetos rituais, fogo, etc. A pluralidade considerada, busca descrever a complexidade de uma festa que reúne e evidencia uma série de relações constitutivas das pessoas e dos lugares onde vivem. O objetivo é demonstrar que a township é um espaço de criação de formas estéticas que subvertem os constrangimentos do passado e dão lugar a uma modernidade original em que o rural desempenha papel fundamental.

As perguntas subjacentes aqui são: existem casas redondas nas townships para abrigar rituais que se relacionam aos ancestrais? Como uma cabra entra no ciclo de reciprocidade e sacrifício em um ritual realizado na township? As roupas tradicionais zulu - feitas de couro, escudos e miçangas - podem ser usadas na township, onde predominam as roupas ocidentais? O que dizer dos cabelos elaborados em casa - na intimidade - e no salão de beleza: uns são mais modernos que outros? A razão prática é suficiente para responder à cocção de alimentos em grandes panelas sobre fogueiras no terreiro da casa da township, quando é necessário preparar comida para as mais de cem pessoas que irão atender ao ritual? Casar na igreja metodista, trocar presentes com os mortos, entoar a ululação e fazer uma festa em que se ouve kwaito nas alturas indica que o casamento zulu está, aos poucos, deixando de ser tradicional?

As coisas não acontecem como se um espelho distorcido refletisse as práticas do universo rural na township, onde semelhanças e diferenças seriam amplificadas ao sabor das bizarrices do reflexo. O espelho também não pode ser encarado como a soma de suas partes colapsadas depois de um tombo, quando se acrescentam peças novas àquelas arredias ao re-encaixe.

\footnotetext{
${ }^{3}$ Thokosa é uma das townships que orbitam Johanesburgo, situada no sudeste da província de Gauteng, em direção aos limites da província de Free State. É uma cidade onde vivem pessoas oriundas de diversos lugares da África do Sul e de diversos grupos linguísticos, além dos estrangeiros do continente africano. Entretanto, conta com uma maioria de falantes de isiZulu e isiXhosa. Inclusive, em sua história recente, na transição para a democracia, Thokosa foi palco das mais sangrentas batalhas entre partidários do Inkhata Freedom Party - de base ética zulu - e do African National Congress - mais universalista - na transição para a democracia.
} 
Inspiro-me no trabalho de Rebekah Lee sobre a morte e as empresas funerárias, para considerar o modo como a modernidade é vivida na África do Sul urbana sem que as referências ao universo rural sejam apagadas. Em seu estudo sobre a "morte na estrada", a autora investiga os procedimentos relativos ao enterro e cuidado dos corpos dos defuntos. Nos últimos 20 anos, essa prática passou a ser alvo de um rentável negócio em Cape Town: as associações funerárias formais e informais - o que permitiu até mesmo aos mais pobres arcar com as despesas dos enterros que implicam no transporte do defunto e das pessoas que atendem ao funeral das townships para as áreas rurais (Lee, 2011: 226).

Essa prática não é nova. Conforme Lee, desde o início da migração para as minas do Rand (final do século XIX), a morte era mais temida por ocorrer longe de casa do que prematuramente. Não haveria maior indignidade que ser enterrado nos cemitérios localizados nas propriedades das minas. Como resposta a esta situação, foram criadas as primeiras associações funerárias e em 1955 os cemitérios das minas pararam de operar (Lee, 2011: 228).

$\mathrm{Na}$ atualidade, a consolidação de uma população africana urbana se mostra um perigo a essas empresas, que não lucrariam mais com o transporte dos corpos da township para as áreas rurais. Uma das estratégias para o negócio tem sido o incentivo de práticas tradicionais africanas em torno da morte no contexto urbano, como o ritual de enrolar o corpo do defunto com cobertores. Além dessa prática dignificar o morto em seu funeral algo impossível durante o apartheid - Lee também considera o seguinte: o ressurgimento do tradicional reitera a autoridade moral do "rural" que, por sua vez, ajuda a manter a necessária política de distanciamento crucial à dinâmica migrante (Lee, 2011: 234).

Seja através do deslocamento dos defuntos - que contam com as novidades do embalsamento e da exumação - para as áreas rurais ou do deslocamento de práticas tradicionais para a township, existe, nas palavras de Lee, "uma interrogação dos africanos em relação as suas próprias histórias de migração que se referem ao processo de urbanização" (Lee, 2011: 229). Ou seja, não se trata de uma re-leitura da tradição na modernidade ou de uma atualização de práticas rituais pretéritas.

Se, por um lado, as migrações, a urbanização e a segregação espacial e racial explicam muito sobre os afastamentos, as perdas e as tentativas de solucionar as equações de dano, por outro, explicam muito pouco sobre o sentimento de pertencimento a um lugar 
através de outro(s), ou seja, sobre a agência dos lugares em face aos deslocamentos. Grandes parcelas de invisíveis são convidados de honra nas persistentes práticas rituais como os funerais e os casamentos - que nos ensinam sobre as trajetórias de desterro como uma questão em permanente negociação. Na township, múltiplas agências - dos sujeitos, dos lugares e dos elementos que compõem as práticas rituais - se combinam para a produção dos efeitos desejados.

Os elementos que compõe um ritual de casamento em uma township sul-africana evidenciam os vínculos mantidos com as áreas rurais mesmo após meio século de migração. As pessoas partiram, por razões relacionadas ao apartheid e ao crescimento urbano, mas suas casas originais nas áreas rurais ou os túmulos de seus ancestrais, permaneceram como uma referência imutável em face as mudanças (Azevedo, 2013). Há uma hierarquia que marca as experiências de mudanças de casas e faz com que o trânsito entre diversas localidades tenha um eixo de orientação. Conforme Borges, as experiências de viver em diversos lugares é uma marca comum entre os negros sul-africanos:

[Gracie], como quase todas as pessoas adultas que conhecemos, viveu por algum tempo de sua vida em Johanesburgo. Lá obtiveram empregos e alguma fonte de rendimento. Assim como Gracie, em outras situações, as pessoas acabavam por ter também uma casa em uma township, além da casa no interior da fazenda de um proprietário branco. Essas três casas (nas grandes capitais, na township, na fazenda) remetem a eixos de orientação presentes na vida de quase todos. (2011: 239).

Essa observação, por si só, já subverte a conformidade e indica uma escolha. Os deslocamentos poderiam ser marcas indeléveis de uma diáspora sem fim, mas, não. Desde o princípio, marcadores fundamentais de uma certa cosmologia composta por uma ontologia fazem referência ao passado, aos ancestrais e ao universo rural como se esses fossem o presente, os vivos e o universo moderno, atual. Separações entre lugares, temporalidades e formas de humanidade constituem a segregação racial e espacial sul-africana industrial e pós-industrial, o que não significa dizer que os sujeitos que tentam ser fisgados por esta armadilha tenham caído nela.

Os protagonistas do casamento em questão são de origem zulu e ndembele. A família do noivo - com quem mantive intimidade e vivi ao longo de meu trabalho de campo durante a pesquisa de doutorado - é oriunda da província de KwaZulu-Natal e se define como zulu nos dias atuais. Já a família da noiva - com quem convivi apenas durante o 
casamento - vive em Sebokeng (uma township próxima a Thokosa) e a identidade étnica acionada durante a festa foi a ndembele.

Como ficará claro nas páginas seguintes, um casamento entre falantes de isiZulu é um evento que termina na casa do noivo, quando a noiva se muda para lá ${ }^{4}$. Porém, em seu desenvolvimento, outras casas são conectadas, como a casa dos pais da noiva e do noivo. Se considerarmos que as experiências de mudanças são uma regra na vida dos sul-africanos negros, é bastante comum que as diversas casas envolvidas nesses rituais se refiram a mais de uma localidade.

O horizonte geográfico das relações familiares, portanto, não se circunscreve a um bairro em uma township ou a uma área rural, exclusivamente. Isso não significa, no entanto, que as pessoas não mantenham relações sociais importantes nos lugares em que vivem. Mas, certamente, são as relações familiares e ancestrais (aquelas que movimentam os rituais permanentes e de toda a sorte, como aniversários, festas de graduação, rituais de aviso de mudança de casa, funerais, casamentos, rituais dedicados aos ancestrais, etc.) que fundamentam as noções de pertencimento a um determinado lugar, mesmo que essas noções se deem através de outros lugares.

\section{Why are we going to sleep? There's a wedding!}

Alguns dias antes do casamento em Thokosa, viemos de Ingogo (área rural de KwaZulu-Natal) com o carro cheio de pessoas espremidas em meio aos potes para a cerveja dos ancestrais e as bandejas para a carne sacrificial. Uma viagem entre essas duas localidades raramente é solitária, sempre há alguém em busca de carona. Os motivos dos deslocamentos vão desde simples visitas, trabalho, estudos, mudanças, até a urgência dos funerais. Naquela ocasião, além de pessoas, os objetos rituais também nos faziam companhia.

Depois de quatro horas de viagem, adentramos Thokosa, calada e vazia. Como é notório em toda a África do Sul, inclusive nas capitais das províncias, pouca gente caminha

\footnotetext{
${ }^{4}$ Os zulus são definidos como exogâmicos, com descendência patrilateral e residência patrilocal por ocasião do casamento. Efetuam considerável prestação matrimonial - o lobola - do grupo de parentes do noivo para os parentes da noiva. Os filhos gerados em uniões consolidadas por este pagamento recebem o sobrenome paterno e residem com os parentes paternos, sem direitos junto aos parentes maternos.
} 
pelas ruas depois do sol se pôr. Em contraste à atmosfera cotidiana das noites silenciosas, nossa chegada calorosa rompeu o mutismo através de buzinadas estridentes e do alto volume de gospel que ouvíamos no carro. Em contrapartida, fomos recepcionados com ululação e alegria pela família do noivo, que nos recebia em casa de portas abertas. A mãe do noivo estava devidamente trajada com o seu hlonipho 5 nas costas, o que indicava que algo extraordinário acontecia naquela casa.

Mal dormimos e, na manhã seguinte, fomos com a mãe do noivo ao centro de Johanesburgo, na especializada Market Street, em busca de tecidos. Ela era uma costureira profissional e produzia as roupas do casamento do filho, especificamente, aquelas que seriam usadas no dia de ir à igreja. Ali, visitamos diversas lojas e, na vitrine de uma delas, pude conhecer o traje feminino zulu que deveria ser usado pelas mulheres da família do noivo durante a troca de presentes conhecida como umabo ${ }^{6}$.

O traje consistia em uma saia preta plissada, blusa preta, cinto, bracelete, colar grosso e chapéu preto - tudo bordado com miçanga colorida. A roupa era bastante cara e custava 750 rands (185 reais). A mãe do noivo aconselhou-me a não comprar nada ali, pois uma de suas filhas havia trazido, de Durban, uma série de adereços que seriam distribuídos entre as mulheres da família.

A casa dos pais do noivo estava em reforma para receber as novas mudanças. $\mathrm{O}$ quarto do noivo era alvo de ampliações, pois ali, a noiva e a filha do casal também passariam a morar depois do casamento. Essa casa guardava semelhanças estruturais em relação as casas das áreas rurais, em que os pais de uma família vivem com seus filhos solteiros e casados, e suas filhas solteiras. Um conjunto de casas-quarto dá forma ao "zulu homestead" que é composto também por uma casa redonda e o kraal (uma espécie de curral onde as relações entre animais, ancestrais e pessoas são efetivadas). No caso da township, a divisão espacial ficava por conta de puxadinhos no terreno que abrigavam os filhos solteiros e casados, enquanto as filhas solteiras dormiam em um quarto dentro da casa dos pais.

Naquela casa, entretanto, não havia objetos rituais, nem nada semelhante ao kraal ou a uma casa redonda - onde moram os ancestrais. Por ocasião do casamento, os objetos

${ }^{5} \mathrm{O}$ hlonipho é um pano usado pelas mulheres em momentos rituais, como a morte ou o casamento.

${ }^{6} \mathrm{O}$ umabo, junto ao umembheso e o lobola são as principais prestações matrimonias trocadas entre os falantes de isiZulu. 
foram trazidos de KwaZulu-Natal, como os potes para a cerveja e as bandejas para a carne, assim como os ancestrais que, meses antes do evento, foram convidados pelo noivo e seu pai a comparecerem à township através de um pequeno ritual em que uma cabra fora sacrificada.

A chegada dos objetos rituais e dos ancestrais à Thokosa foi marcada pela transformação de um barraco, nos fundos do terreno, em uma casa redonda. No chão, em frente à porta do barraco foram colocados os potes com sangue fresco sacrificial e cerveja a fermentar. Do lado fora, no terreno, a comida que seria compartilhada ao longo de diversas cerimônias por muitas pessoas era cozida em grandes panelas pretas sobre o fogo no chão.

As festividades foram iniciadas em uma tarde de quinta-feira, quando uma comitiva saiu de Thokosa em direção à township de Sebokeng, onde a família da noiva nos aguardava para receber os presentes (roupas) e o dinheiro que finalizariam as negociações acertadas previamente sobre o pagamento do lobola. Quando chegamos lá, todos se organizaram em fila e começaram a cantar que iriam entrar na casa bem devagar, que Buthelezi - o pai do noivo - as tinha mandado. Para surpresa de quase todos, uma ovelha foi retirada do porta-malas de um dos carros e todo o movimento da dança, que ritmava os nossos passos em direção ao portão da casa, foi tonificado pela presença do animal, preso entre as pernas de um dos rapazes que avançava lentamente com ela.

A ovelha foi amarrada no terreno da casa, enquanto a troca de presentes se desenrolou dentro de casa. Os familiares falecidos da noiva recebiam presentes, assim como os vivos. Esse ritual íntimo contou apenas com as respectivas famílias e, a não ser pelos cantos entoados na nossa chegada, não houve mais nada ali que tornasse público o evento.

Na sexta-feira, dia que antecedia o casamento na igreja e uma festa em Sebokeng, os cabelos foram os protagonistas e receberam tanta atenção quanto as roupas. Todas as mulheres tiveram seus cabelos elaborados com um aplique, uma peruca ou um simples enfeite. Uma delas havia ganhado de presente do namorado uma extensão bem cumprida e foi ao cabeleireiro aplicá-lo, algo dispendioso e pouco usual entre as pessoas com quem convivi. Naquela noite, quando eu me encontrava exausta e não acreditava que a fila para arrumar os cabelos com o secador ainda fosse se prolongar madrugada adentro, perguntei se não iríamos descansar para o dia seguinte na igreja, ao que me responderam: "Why are we going to sleep? There's a wedding!" 
Quando os taxis ${ }^{7}$ e os carros particulares se juntaram na porta da casa dos pais do noivo, na manhã de sábado, a máquina de costura ainda trabalhava nos últimos acertos dos ternos que seriam usados pelos familiares do noivo. As mulheres colocavam seus vestidos, calçavam sandálias altas e aplicavam enfeites de flores nos cabelos já devidamente elaborados. Assim que ficavam prontas, as pessoas seguiam para a igreja em Sebokeng nos carros disponíveis. O noivo partiu em um carro todo enfeitado com balões coloridos. O barulho das buzinas era constante e anunciavam o evento.

Chegamos à igreja antes da noiva. Algumas pessoas já se encontravam ali, no terreno da igreja, com uma banda. Havia pessoas vestidas com trajes tradicionais, com roupas feitas de tafetá, mulheres usando shweshwe ${ }^{8}$ e pessoas usando roupas mais simples, além de outras que não faziam parte da cerimônia, se vestiam comumente, mas se somavam, curiosas, em torno da igreja.

Ao contrário da igreja pela manhã, à tarde, nos arredores da casa da família da noiva em Sebokeng, havia tanta gente quanto era possível. Além das famílias dos respectivos noivos, amigos e uma imensidão de vizinhos se juntavam aos convidados. Não havia lugar para todos sentarem nas cadeiras e mesas espalhadas pelo terreno da casa. Embora duas tendas tivessem sido alugadas para abrigar os convidados, a maior parte das pessoas se aglomerava na rua sem calçamento, enlameada pela chuva. Os homens, em especial, aproveitavam a ocasião festiva para beber cerveja industrializada.

Quando os noivos chegaram, houve uma espécie de cortejo no qual todos dançaram e cantaram ao som de uma música pop americana. Depois disso, os noivos se dirigiram para uma das tendas, onde se acomodaram para que a comida tradicionalmente oferecida nos rituais fosse servida: salada de beterraba, arroz, carne de vaca cozida e purê de abóbora. Quando a refeição terminou, a festa seguiu seu curso, noite adentro, ao som de grandes caixas que entoavam música americana e kwaito em alto volume. O kwaito é assim definido por Nuttall:

South Africa's globally recognized local music form a potent blend of city and township sound that emerged after the democratic transition in 1994, mixing the protest dancing

\footnotetext{
${ }^{7}$ Taxi é o nome dado as vans de transporte alternativo na África do Sul.

${ }^{8} \mathrm{O}$ shweshwe é uma roupa tradicional sotho, também considerada uma roupa tradicional zulu, confeccionada com o tecido da marca Three Cats.
} 
and chanting known as toyi-toyi with slow-motion house, local pop (known as 'bubblegum'), and a dash of hip-hop. (Nuttall, 2008: 94).

A reforma no quarto do noivo já estava quase finalizada e, na manhã de domingo, as paredes estavam sendo pintadas por homens jovens vestidos de guerreiros zulu. As mulheres jovens da casa haviam recebido colares e braceletes de miçangas, e sandálias de dedo feitas de couro com pelos. Entre homens e mulheres jovens solteiros, havia mais de dez pessoas com roupas e adereços zulu. Elas se dirigiram para a frente da casa, na rua, onde uma pequena aglomeração de familiares se formou em torno dos dançarinos que, a esse ponto, chamavam a atenção com seus cantos, ululação, dança e roupas. Aos poucos, uma multidão de amigos e vizinhos invadia a rua para ver os dançarinos, que abriam espaço para uma pessoa no centro da roda fazer a gida ${ }^{9}$ ao ritmo das palmas coletivas.

Passado algum tempo, a noiva chegou, acompanhada de outras mulheres. Surgiram de uma das extremidades da rua e andaram em meio às pessoas, que abriram espaço para que elas passassem e alcançassem os dançarinos zulus. Elas estavam vestidas com adornos ndebele - colares de argolas douradas no pescoço.

$\mathrm{O}$ encontro dos zulus e das ndebeles foi marcado por uma dança em que os grupos rivalizavam, como se disputassem a noiva ${ }^{10}$. Depois de performatizada a disputa, a noiva e suas acompanhantes entraram na casa dos pais do noivo com os presentes do umabo: esteiras, cobertores e travesseiros, enquanto as pessoas do lado de fora seguiam dançando.

Ao fim da troca de presentes, os noivos tiraram suas roupas tradicionais e se vestiram com blazer e vestido de festa, assim como os outros. Saíram dançando da casa, seguidos pela multidão na rua. Os carros particulares e os taxis levavam as pessoas para o hall ao som das buzinas e da ululação.

O hall era um espaço alugado para a recepção de eventos nas redondezas de Thokosa. Havia lugar para mais de duzentas pessoas. O DJ colocava o som de música pop americana que abafava a ululação. Os primeiros a dançarem foram os noivos, que performatizaram uma coreografia sob os olhares dos convidados. A janta servida naquela noite era composta

\footnotetext{
${ }^{9}$ A guida é uma dança ritual em que se joga uma das pernas até a altura da cabeça e que, ao descer, finaliza o movimento com uma forte pisada no chão, sincronizada a uma batida das palmas.

${ }^{10}$ Conforme Kuper, no casamento entre os zulus, a expectativa é de que os dois grupos envolvidos tenham um status social igual. No entanto, se acredita na superioridade de uns sobre os outros, o que incita os grupos a se mostrarem superiores nas "danças de casamento" (Kuper, 1982: 136).
} 
da tradicional comida dos rituais e fora preparada sobre as fogueiras da casa dos pais do noivo, apesar de haver uma cozinha semi-industrial no hall.

A festa se desenrolava ao som de kwaito, muita dança e bebidas alcoólicas. Com o avançar da noite e do frio, os convidados partiram com as caronas que surgiram, embora alguns tenham seguido para um bar em Thokosa - como a moça que pegou o buquê e foi deixada na casa em que eu me hospedava sob os primeiros raios de sol da segunda-feira.

Aparentemente, o casamento tinha chegado ao fim. Na segunda-feira, encontramos a casa dos pais do noivo, pela primeira vez, ao longo daqueles dias, em silêncio e com as portas fechadas. Ao entrarmos na casa, a noiva servia um café da manhã especial para sua sograria. A mãe do noivo estava triste pela partida de todos. Ela mesma iria conosco para KwaZulu-Natal por ocasião de um funeral.

No carro em que viéramos, voltaríamos agora com mais uma companhia, além de uma máquina de costura movida a pedal no porta-malas. Ao nos despedirmos, ganhei de presente uma xícara e um pires da noiva, em agradecimento por ter comparecido ao seu casamento. Ela agora não era mais chamada por seu nome, Sibongile, e, sim, de maNhlanhla, mãe de Hlanhla.

\section{Transformações estéticas, espaciais e animais}

Demorei muito tempo para compreender a complexidade do que minhas interlocutoras falavam a respeitos das roupas que iriam usar no casamento, pois não se tratava de uma única roupa, mas de várias, para diferentes ocasiões. Diziam que no dia de ir à igreja deveriam usar vestidos de tafetá nas cores roxo e cinza, pois essas cores figuravam no convite do casamento e significavam que os noivos as usariam. Além dessa roupa, deveriam usar a roupa tradicional zulu comprada em Durban - pois "o noivo é zulu”, diziam, e assim estaria vestido.

Curiosamente, a roupa considerada tradicional zulu é justamente aquela comprada em Durban (capital da província de KwaZulu-Natal, onde vive a maior parte dos falantes de isiZulu). Essa é a cidade sul-africana em que a comoditização da etnicidade surge através

do comércio massificado de produtos étnicos, sendo esse o caso, por exemplo, das miçangas, que encontram ali o seu entreposto comercial de maior destaque (Winters, 2008: 
419). É também o lugar, naquele país, em que há o maior mercado de consumo de espetáculos étnicos, como as danças tradicionais zulu encenadas para turistas. Entretanto, a despeito do caráter comercial que os objetos etnicizados possam apresentar - como é o caso dos adereços feitos com miçanga -, os Comaroff escrevem que eles "resistem à racionalidade econômica" e que o status do que chamam de "embodied ethnic subject" são fonte e meios de identidade (Comaroff \& Comarroff: 2009: 20).

Uma terceira roupa, chamada de shweshwe, parecia ser uma alternativa à roupa tradicional zulu. Considerado igualmente tradicional, era comumente usado e confeccionado por mulheres mais velhas, como a mãe do noivo, uma especialista nesse tipo de vestimenta. Definido como uma roupa tradicional sotho, feita com o tecido da marca Three Cats, o shweshwe se tornou também uma roupa tradicional zulu. Por sua vez, os sothos consideram o shweshwe uma vestimenta com design sotho, feita com tecido alemão, que passou a ser considerada uma roupa tradicional das mulheres sotho (Khau, 2012: 109).

Há uma série de operações em jogo nas escolhas estéticas, mas o fundamental é que as pessoas definem aquilo que consideram tradicional e sabem onde e quando devem exaltar essa identidade. Mesmo que tudo parecesse confuso para alguém como eu, não havia nenhuma confusão na apropriação da roupa tradicional dos outros - o shweshwe -, nem na compra da sua própria roupa tradicional de miçangas em Durban, muito menos na eleição de vestidos de tafetá roxo e cinza para ir à igreja e ao hall.

Inclusive, as inúmeras roupas para diversas ocasiões que tanto me confundiram, apareceram na igreja, como em nenhum outro momento do casamento, todas juntas, sem significar confusão para aqueles que as usavam. É curioso que isso tenha ocorrido justamente no lugar onde talvez a expectativa em torno da tradição seja colonizada e esfacelada. Esse evento me fez recordar a famosa inauguração da ponte descrita por Gluckman (1987), quando o autor buscava alcançar um continuun de "padrões de comportamento zulu-europeus" através das roupas européias compartilhadas por zulus, esquecendo de mencionar que os europeus não se vestiam com roupas zulus. Na igreja em Sebokeng, assim como ao longo de todo o casamento, as roupas indicavam uma demarcação, bastante nítida, de todo o universo social dessas pessoas através de suas opções estéticas. 
Além das roupas, os cabelos também desempenharam papel importante. Neste caso, não se tratava da demarcação de identidades em face aos diferentes eventos e, sim, da marcação dos ritmos da vida social pela "elaboração ritual da cabeça" (Cruz, 2012). Em texto seminal sobre o cabelo, Leach (1983) chama a atenção para a análise dos rituais do cabelo, quando lhes confere um status comunicativo semelhante ao atribuído por Malinowski à linguagem - que defende que as palavras não servem simplesmente para comunicar algo, elas alteram o estado das coisas (Leach, 1983: 140). Entre as mulheres com quem trabalhei, cada ocasião pedia um cabelo diferente. Os penteados eram variados, não havia um protocolo a seguir, o importante era a mudança.

O trabalho de Cruz (2012) sobre os cabelos em Maputo, Moçambique, ecoa na centralidade dos mesmos entre as pessoas com quem trabalhei na África do Sul. Em primeiro lugar, o modo como os cabelos se destacam nas práticas corporais dessas mulheres não deve ser entendido sob a mesma perspectiva dos cabelos de "afrodescendentes" no contexto americano. Portanto, não se referem à "alteração" e à "insatisfação corporal" inseridas na discussão sobre as relações raciais onde os cabelos "deveriam ser algo que expressam o 'ser' (no caso, 'ser negro')". Embora a África do Sul seja marcada por um contexto de hierarquização racial, assim como Moçambique, o foco nos cabelos não diz respeito à "reprodução de padrões de beleza dominantes" (Cruz, 2012: 2).

Os cabelos falam dos movimentos mais cotidianos, como aqueles que ocorrem das áreas rurais para as cidades, onde jamais se chega com uma touca, adereço comum nas fazendas. Já os cabelos produzidos durante o casamento indicavam uma colaboração maior que contava com a ajuda de diversas pessoas para desembaraçar, trançar ou escovar os cabelos no quarto transformado em salão de beleza particular. Era uma ocasião em que ir ao cabeleireiro também se tornava possível, acaso houvesse demasiadas expectativas em torno de um penteado, como ocorreu com uma das mulheres com seu longo aplique dado pelo namorado.

Além das transformações estéticas das pessoas, os espaços da township ganharam também novos contornos. Antes do casamento, não havia nada que fizesse as vezes de casa redonda em Thokosa. Afinal, não havia ancestrais naquela casa - eles haviam sido deixados em KwaZulu-Natal ao longo das mudanças que marcaram a vida da família. Entretanto, foi 
criado um lugar para a sua recepção - o barraco - que, embora não fosse redondo, subvertia as formas quadradas das casas das townships.

Atualmente, as casas nas áreas rurais assemelham-se as casas quadradas das townships, cujas paredes são erguidas com tijolos de cimento pré-moldado e os telhados feitos de chapa de zinco. Porém, quando se trata da casa dos ancestrais - ou seja, a casa redonda -, há uma predileção pela forma arredondada erguida com uma mistura de esterco e terra, e coberta com capim, pois dizem que os ancestrais só conhecem esses materiais. White acrescenta que as casas quadradas, com telhado de zinco e divididas internamente, são chamadas de "iflethi [anglicismo de flat (plano)]" em oposição as casas "isikwele [circulares]", sem divisões. As diferenças na forma são relacionadas por White a diferenças na denominação, onde as casas nomeadas através do anglicismo seriam mais distantes da “zuluness" (White, 2010: 512).

Embora haja uma preferência por certos tipos de casas e seus materiais, White perde a oportunidade de perceber que a forma das casas independe de sua arquitetura - e que umas não são mais originais que outras. A "zuluness" das casas está principalmente no modo como as pessoas vivem o espaço, e esse espaço é o da imaginação, e não o da reminiscência de um passado inalcançável.

As transformações, como a do barraco que vira casa redonda ou da casa de township que se assemelha estruturalmente aos "zulu homesteads", subvertem as formas pretéritas dos lugares de tal maneira que é possível falar em criação de um novo espaço e não somente de transformação, já que esse independe das paredes circundantes ou do teto, pois é performativamente fabricado e constantemente vivido, seja pelas pessoas ou por seus ancestrais.

Conforme Ingold, em sua análise sobre a "morada", há práticas que constituem o "morar": o que fazemos e que constituem os espaços em que vivemos em nossos lares. Essas práticas se diferenciam da ideia simples de "habitar" um espaço já construído (Ingold, 2000: 172-188). Nesse sentido, os espaços arredondados seriam literalmente criados, não estariam ali antes, porque sua existência é constituída pelas práticas de "morada" que, nesses casos, dizem respeito não somente as práticas dos vivos, como também de seus ancestrais. 
Nessa relação, o fogo parece ser um elemento essencial - assim como os elos criados por animais - para que vivos e ancestrais se enxerguem mutuamente. As práticas de "morada" dos ancestrais que chegam e passam a estar presentes nesses espaços se tornam visíveis pelo modo como eles fazem as coisas: vivem no chão, sua bebida (a cerveja) e sua comida (o sangue) devem ser postas ao seu alcance. Gostam de morar em lugares onde se sintam protegidos: com uma entrada, mas sem saída - defronte à porta. É desse modo que também entendemos a insistência em se cozinhar no terreno sobre o fogo no chão, mesmo com a disponibilidade de uma cozinha altamente equipada no hall alugado para a recepção dos noivos.

Já os animais, como ovelhas e cabras, fazem parte da classe especial de presentes trocados entre as famílias, assim como roupas, dinheiro, esteiras, travesseiros e cobertores. Além disso, os animais são sacrificados, de acordo com um ritual preciso, em que o intuito é a comunicação com os ancestrais.

Ao serem dados como presentes, os animais "percorrem o caminho das interações domésticas e se tornam expressões das trocas locais”. Essas observações são feitas por White a respeito das diferenças entre o frango comprado no supermercado e aquele criado em casa - onde entram como pintinhos, presentes, commodities. O primeiro tipo de frango é chamado pelo autor de "comida de whiteness" e o segundo de "comida de zuluness". Consumida pelas mesmas pessoas em diferentes ocasiões, a comida derivada de animais corresponde a "diferentes estruturas de personalidade e proximidade" (White, 2011: 105107).

Os animais que participaram desse casamento foram comprados em criações das redondezas, porém, ao entrarem no circuito de troca, sacrifício e consumo transformavam a sua "whiteness" em "zuluness" (para usar as expressões de White), ao contrário do que ocorre com a comida cotidiana, e produziam sinais na comensalidade que distinguiam as pessoas. A comida ritual, servida nas diversas ocasiões comunicava as famílias ou era consumida por apenas um dos grupos envolvidos no casamento. Além disso, em cerimônias de maior magnitude, amigos e vizinhos eram também convidados a partilhar o alimento. 


\section{Movimento na township}

O contraste entre o cotidiano de uma township e os dias de casamento era notório, em especial, pelo barulho que anunciava, mesmo aos vizinhos mais distantes, um acontecimento especial nas redondezas. Fosse durante o dia ou à noite, a ululação, os cantos, a música alta e as buzinas chamavam a atenção para um evento que teve seus momentos de intimidade, mas, em sua maior parte, era público e contava com a participação de pessoas que extrapolavam o universo familiar, como os amigos e os vizinhos.

O movimento de pessoas era incessante, seja daqueles que chegavam de lugares mais distantes para compor a festa ou daqueles que trabalhavam, já que não se contava com quase nenhuma espécie de terceirização na organização do evento. As coisas que deveriam ser feitas para que tudo ficasse pronto a tempo eram muitas e mobilizavam a todos.

Em todos os rituais de que participei ao longo do trabalho de campo na África do Sul nos anos de 2010 e 2011, o trabalho era uma característica marcante, por ser desempenhado de modo incessante por todos os envolvidos (homens, mulheres, velhos, adultos e jovens). Entretanto, o casamento se distinguiu entre os demais rituais pela sua extensão temporal e espacial. Muitas cerimônias, que atravessam dias e lugares, compõem o casamento entre os falantes de isiZulu. Para que uma noiva mude para a casa do noivo, é preciso comunicar uma série de pessoas e lugares envolvidos nessa passagem. Ancestrais, familiares, amigos e vizinhos, são todos convidados a testemunhar, em diferentes instâncias - como a igreja, as casas dos respectivos noivos, seus lugares de origem ancestral, a rua e os espaços alugados para festas - os rituais que propiciam a mudança de casa, das relações sociais, dos espaços e das formas de pertencimento.

As transformações estéticas, espaciais e animais percebidas ao longo dos movimentos desencadeados pelo casamento, nos informaram sobre as conexões espaciais de pessoas cujas vidas foram marcadas por mudanças. O que não significa que elas tenham se desfeito de seus laços originais ou de suas práticas rituais. As transformações observadas nos advertem sobre a criação de novas formas, às vezes, de difícil compreensão, por nos escaparem da visão, mas que são permanentemente fabricadas e negociadas diante das mudanças. 


\section{Referências}

AZEVEDO, Aina. Cosquistas cosmológicas: pessoa, casa e casamento entre os Kubheka de KwaZulu-Natal e Gauteng. Tese de doutorado defendida no Programa de pós-Graduação em Antropologia Social da Universidade de Brasília, 2013.

http://www.scribd.com/doc/213455720/2013-AinaGuimaraesAzevedo

BORGES, Antonádia. Sem sombra para descansar: etnografia de funerais na África do Sul contemporânea. Anuário Antropológico, 2010-I, 2011a, pp. 215-252.

COMAROFF, J. L. \& COMAROFF, J. Ethnicity, Inc. The University of Chicago Press: Chicago. 2009.

CRUZ, Denise Ferreira da Costa. Seguindo as tramas da beleza em Maputo. Dissertação (Mestrado em Antropologia) - Programa de Pós-Graduação em Antropologia Social da Universidade de Brasília, 2012.

GLUCKMAN, M. Análise de uma situação social na zululândia moderna. In: FELDMANBIANCO, BELA. Antropologia das Sociedades Contemporâneas. São Paulo: Editora Global, 1987 [1958].

INGOLD, T. 2000. The Perception of the Environment - Essays on livelihood, dwelling and skill. Londres e Nova York: Routledge

KHAU, Mathabo. Gender and the politics of the Basotho blanket. In:MOLETSANE, R.; MITCHELL, C.; SMITH, A. Was it something I wore? - Dress Identity Materiality. Cape Town: HSRC Press. 2012.

KUPER, Adam. Wives for cattle - Bridewealth and marriage in Southern Africa. Routledge \& Kegan Paul: London, Boston, Melbourne and Henley. 1982.

LEACH, Edmund Ronald. Cabelo Mágico. In: Edmund Leach 38 - Antropologia. Org.: Da Matta, Roberto. Ática: São Paulo. 1983 [1958], pp. 139- 169.

LEE, Rebekah. Death 'On the move': Funerals, Entrepeneurs and the Rural Urban Nexus in South Africa. Africa: The Journal of the International African Institute, Volume 81, Number 2, May 2011, pp. 226-246.

MBEMBE, Achille e NUTTALL, Sarah. Introduction: Afropolis. In: NUTTALL, S.; MBEMBE, A. Johannesburg - The elusive Metropolis. Wits University Press: Johannesburg. 2008.

NUTTALL, Sarah. Stylizing the Self. In: NUTTALL, S.; MBEMBE, A. Johannesburg - The elusive Metropolis. Wits University Press: Johannesburg. 2008. 
WINTER, YVONNE. The secrets on Zulu Bead Language and Proportion and Balance of the Zulu Headrest (Isiqiki). In: CARTON, B.; LABAND, J.; SITHOLE, J. Zulu identities: being zulu, past and present. Durban: University of KwaZulu-Natal Press, 2008.

WHITE, Hylton. Outside the Dwelling of Culture: Estrangement and Difference in Postcolonial Zululand. Anthropological Quarterly, vol. 83, n. 3, Summer, 2010, pp. 497-518.

A Post-Fordist Ethnicity: Insecurity, Authority, and Identity in South Africa. Anthropological Quarterly, vol. 85, n. 2, Spring 2012, pp. 397-427.

Recebido em: 30/09/2014

Aprovado em: 20/11/2014 